\title{
Developing renewable energy supply in Queensland, Australia: A study of the barriers, targets, policies and actions
}

\author{
Nigel J. Martin ${ }^{\mathrm{a}, *}$, John L. Rice ${ }^{\mathrm{b}}$ \\ a ANU College of Business \& Economics, The Australian National University, Canberra, Australian Capital Territory 0200, Australia \\ ${ }^{\mathrm{b}}$ Griffith Business School, Griffith University, Gold Coast, Queensland 4215, Australia
}

\section{A R T I C L E I N F O}

Article history:

Received 30 November 2011

Accepted 9 January 2012

Available online 31 January 2012

\section{Keywords:}

Actions

Electricity

Energy

Firms

Renewable

Target

\begin{abstract}
A B S T R A C T
The Australian Government has set an ambitious target that at least 20 per cent of Australia's electricity needs will be met by Renewable Energy (RE) sources by 2020. Given the limited use of RE sources for electricity generation, this national Renewable Energy Target (RET) leaves state, territory and municipal governments in a challenging policy position. In this article, we examine the Australian state of Queensland where RE provides approximately 4 per cent of the region's electricity supplies. The research utilizes stakeholder theory to examine the developmental barriers, targets, policies and actions identified by firms and stakeholder organizations in the RE industry sector. The results from our analysis show that RE developments face a range of socio-technical barriers that require timely actions in the areas of financial incentives, infrastructure enhancement, regulation reform, community-centred developments, technology and workforce investments, and information and education programs. Also, in the context of RE planning, while the national RET is the preferred setting, the differences between Queensland's RE installed generation capacity and electricity supply targets require clarification and agreement.
\end{abstract}

(c) 2012 Elsevier Ltd. All rights reserved.

\section{Introduction}

In 2009, the Australian government legislated a Renewable Energy Target (RET) of 20 per cent by 2020 (i.e. approximately 45,000 GWh of RE sourced electricity) in-line with its national plan for a clean energy future $[1,2]$. While the plan is aimed at directly mitigating the impacts of climate change, the flow down of this target and the development of Renewable Energy (RE) supply at the state, territory and municipal levels of government presents a significant challenge $[3,4]$. Accordingly, the impositions of a poor RE development framework for RE asset construction and deployment may render the national RET unachievable in the remaining timeframe.

Important in the context of our study, the policy opportunities that have been canvassed by various researchers and $\mathrm{RE}$ advocates provide a series of policy prescriptions and actions that support the achievement of the RET and any state-level targets [5]. These initiatives can take various forms, including RE Portfolio Standards (RPS), government tendering of RE projects, tax benefits for RE

\footnotetext{
* Corresponding author. Room 3.20, Building 26c, ANU College of Business \& Economics, The Australian National University, Canberra, Australian Capital Territory 0200, Australia. Tel.: +612 61259793; fax +61261254310.

E-mail address: nigel.martin@anu.edu.au (N.J. Martin).
}

assets purchase and depreciation, and voluntary green power markets. However, the selection of RET enabling actions, commencement of the Australian carbon pricing legislation in mid 2012, and the relatively short 10-year timeframe for meeting the national RET, presents some immediate challenges for domestic governments $[2,6]$.

In this investigation, the views of firms and stakeholder organizations confronted with RE policies and governmental actions in the Australian state of Queensland are the primary subject of our analysis. In sum, we seek to answer three major research questions. First, what are the barriers and impediments to increasing RE in national regions and states? Some studies show that RE solutions often face difficult technical, institutional and economic problems and impediments (e.g. poor financing arrangements, high technical risks, unhelpful regulation, faulty market systems) [7-9]. In a pragmatic sense, understanding the various contextual impediments faced by firms and stakeholder organizations would be instructive for researchers and industry practitioners. Second, should state or regional governments establish targets for RE supply? For example, while some countries apply targets to specific RE sources (e.g. wind, solar, biomass) [11-14], Australia allows its states and regions to establish their own renewable energy plans, policies and targets (e.g. the New South Wales (NSW) state government has adopted the national RET as its target [4]. In tracking its progress, a recent independent audit of NSW electricity 
supply showed that 6.8 per cent of that state's electricity supply is currently being met by RE sources, while electricity prices have risen by 6 per cent due to generators' RET commitments) [15]. However, other studies show that striving to meet an RET might result in the creation of multiple policy and regulatory instruments [12] while also delivering less positive outcomes, including increased unemployment and reduced energy security [14]. Given this background, it is important to understand the benefits and problems associated with setting state-level RETs. Finally, what actions should states and regions take in order to meet national level RETs? Our extant RE literature argues successfully that various government policies and actions can aid the growth of RE supplies in regions and countries [16,17]. However, in our case we are specifically examining the views and recommendations of firms and stakeholder organizations that have an exposure to the development of RE sourced electricity in the state of Queensland. Hence, the summation of responses to these questions enables understanding of the context, appropriateness of state-level RETs, and policies and actions that support RE supply expansion.

The balance of our paper is developed as follows. In the next section we will discuss and contrast some of the critical RE literature and theory related to our study, including a detailed explanation of the research setting. Next, the study will describe our structured research method, including the data collection and analysis procedures, followed by a presentation of the results and their discussion. Our concluding statements highlight the importance of understanding what barriers and actions firms and stakeholder organizations consider to be important for the growth of RE supply, while noting the research limitations.

\section{Building renewable energy supply - Barriers, targets, policies and actions}

The literature explicating the barriers to RE growth provides an array of socio-technical problems and hurdles that confront firms and industries $[7-9,18]$. In some instances, the problems can take a strong behavioural form, such as the lack of awareness or information to make sound judgments and decisions within the firm [18], while in other circumstances the impediments might be based on poor policy, administrative process or regulatory systems design that deny generators adequate business opportunities $[8,9,19]$. Other barriers to the advancement of RE supply can take the form of unhelpful and poorly designed energy markets [19,20]; suboptimal research and development, heightened technical risks, and limited innovation and knowledge creation in the field of RE systems $[8,18,21,22]$; and, inadequate RE investment incentives and project financing arrangements [5,11,23,24]. In a collective sense, despite the substantial number of identified impediments across the RE literature, disciplinary experts are confident that these barriers may find some level of resolution with the delivery of suitable policies and actions [12,14,16,17]. In this study, the barriers identified by firms and stakeholder organizations should allow us to understand the larger RE business context and operational impediments to meeting the national RET.

Foundation studies show that RETs form part of the larger set of $\mathrm{RE}$ issues [21]. In particular, the literature shows that RE schemes can take a quantitative position (e.g. RETs, quota systems for green certificate trading, bidding and auction systems for carbon credits) or a more price directed stance (e.g. Feed-in Tariffs (FiT), carbon pricing mechanisms) [25]. Accordingly, it is considered quite appropriate that RETs, and possibly targets at the state, regional and municipal levels, form part of a successful RE development framework $[4,26,27]$. The more global views of RETs, shows us that possibly $10-50$ per cent of our primary energy needs will be met through RE sources by 2050 [27]. Specific to this study, an overview of global RETs shows a range of RE sourced electricity generation targets from 20 to 35 per cent by 2020, stretching out to increasingly more optimistic targets and outcomes of 50-80 per cent by 2050 [27]. We also noted that these types of aspirational RETs can sometimes be set at less challenging (more easily achievable) levels in smaller countries (e.g. 3 per cent) [28], while also requiring the application of a strict definition to assure target efficacy (e.g. share of RE sourced electricity generation is based on actual supply or production not installed capacity) [10,25]. However, despite some of the intricacies in setting RETs, we would argue that understanding the types of state-level targets that might be established, and the utility of these targets for firms and stakeholder organizations, will assist and inform the development of effective policies and actions.

Government policies and actions represent the engine room for RE supply development $[16,17]$. Some of our earlier studies in RE technology show us that appropriate policies can act as the glue that supports positive linkages and actions between institutions and actors in communities [21,29]. Indeed, some researchers depict the relationship between policy and actions as simply: "if we establish a specific RE policy goal, then we need distinct programs and technologies to accomplish this" [21,29]. Several other studies point to the requirement for effective policies that offer government assistance packages (where required), investment and financial incentives arrangements, workable policies for RE FiT, cooperative working systems for private and public organizations, industry development and equipment manufacturing assistance, and stimulants and enablers of systems innovation and design [5,8,22-24,30]. Importantly, these types of policy levers can serve as high level frameworks for actions and activities that support the growth and advancement of RE assets, infrastructure, supply and equipment manufacturing [7,13,23,24,26,31]. In this study, we are seeking to explore and expose the types of policies and actions, identified by firms and stakeholder organizations, which may enable the state of Queensland to meet its obligation under the national RET.

\section{Renewable energy supply in Queensland - An overview}

Earlier studies that focused on RE generation in Australia depicted a slow and cautious start for the country [32]. The original 2001 national RET was modest seeking only a nominal 2 per cent of RE supply by 2010, thereby equating to $9500 \mathrm{GWh}$ of electricity from renewable sources [32]. Also, other studies suggested that Australian RE supply developments could benefit from repricing electricity and taking account of carbon-based pollution and other environmental impacts from its dominant coal fired power generators [33]. Arguably, these types of electricity price adjustments could potentially stimulate further interest and investment in RE projects across Australia.

The most recent studies from researchers, and the Australian government, show RE sourced electricity generation in Australia totalling approximately 7 per cent, with abundant fossil fuels still serving as the primary energy source for the country [34,35]. In addition, the latest energy supply trends show that Queensland ranks third in overall RE installed generation capacity behind NSW and Victoria. Accordingly, in order to meet the national RET, each state and territory must play an active role in developing RE supplies.

Queensland is Australia's second largest state covering over 1.9 million square kilometres of land and home to over 4.5 million citizens [36]. The state economy is based on strong mineral resources (mainly coal, bauxite and copper) and tourism sectors, with primary industry production of beef, bananas, sugar cane, pineapples, peanuts, grains, cotton and wool. The state economy is 
founded on competitively priced electricity inputs that are primarily supplied by various coal fired power stations built during the 1980-2000 period [37]. However, this results in Queensland having the highest per capita carbon emissions of all the Australian states and territories [37].

Queensland is also one of six interconnected regions that supply approximately A\$11 billion worth of electricity under a National Electricity Market (NEM) that was created in 1998 [38]. The Australian Energy Market Operator (AEMO) uses a centrally controlled dispatch process to schedule and match electricity producer outputs and consumer usage in a spot price market, where Australian electricity laws and rules provide the operational framework. NEM regulation is provided by the Australian Energy Market Commission (managing the rule making process and assessing proposed rule changes) and the Australian Energy Regulator (monitoring and enforcement of rules and law compliance). Importantly, the AEMO has stated that the current RET will lead to changes in the mix of electricity supply sources and location origins in the coming years, including RE supply from Queensland [39].

In response to the national RET, the Queensland government established the Office of Clean Energy (OCE) in early 2009 to administer the Queensland Renewable Energy Plan (QREP) [40]. The QREP applies to small-medium and large scale RE developments (for the retail distribution and high voltage service provider networks, respectively) and provides the high level framework for the state to achieve its share of the national RET, estimated at $2500 \mathrm{MW}$ installed capacity or $9000 \mathrm{GWh}$ of electricity supply [40]. In executing the QREP, the Queensland government has moved forward with several initiatives and projects as follows.

\subsection{Biomass}

Sugar cane waste (or bagasse) provides approximately 70 per cent of the state's RE supplies. The state government provided A\$9 million, from its A\$50 million Queensland Renewable Energy Fund (QREF), for the development of Mackay Sugar's energy cogeneration plant at the Racecourse Mill near Mackay, North Queensland. In addition to serving the current energy needs of the mill (65 MW), the replacement plant will deliver an extra $27 \mathrm{MW}$ of capacity to the state electricity grid commencing in 2013.

\subsection{Solar (hot water and photovoltaic)}

The high levels of solar resources in Queensland (known as the 'Sunshine State') provide significant opportunities for solar power generation and deployment. The Queensland Solar Bonus Scheme has seen over 30,000 customers install roof top photovoltaic (PV) systems (with a 44 cents per kWh residential gross FiT applied), and over 100 MW installed capacity during 2008-2010. The state government supplemented this with the Queensland Solar Homes Program where a bulk purchase of solar panels allowed 1000 homes to be fitted with PV systems.

A state solar initiatives package valued at $\mathrm{A} \$ 115$ million is being used to fund projects such as Virtual Solar Power Stations (500 MW) in towns and communities (using PV and solar hot water systems); the A $\$ 60$ million Solar Hot Water Rebate Scheme (A\$600-1000 per solar hot water installations); the A\$5.8 million PV system installation program for 420 kindergartens; the A\$9.9 million Solar Sport and Communities initiative to support solar systems installations in sports clubs and community organizations; and, the A\$35.4 million for the Kogan Creek Solar Thermal systems installation.

In addition, the state government has also invested $\mathrm{A} \$ 60$ million in the Solar and Energy Efficiency in State Schools program that will see over 1250 schools fitted with PV systems, and provided another A \$4 million for the Wide Bay Community solar farm to power health services facilities in the Hervey Bay region. The state has also provided A $\$ 5$ million for Townsville's participation in the federal Solar Cities Program, while A\$6.6 million has been allocated from the QREF for solar roof top arrays at the Carrara Gold Coast stadium and the University of Queensland campus, and a solar atlas (radiation recording) project in western Queensland.

At the national level, in June 2011 the Solar Dawn Consortium was awarded a federal Solar Flagships program grant to build a $250 \mathrm{MW}$ solar thermal and gas hybrid plant ( 85 per cent or $212 \mathrm{MW}$ of renewable energy capacity) near Chinchilla in western Queensland to commence operations in 2015 [41].

\subsection{Hydro}

The state operates three small hydroelectricity stations (167 MW) at Barron Gorge, Koombooloomba and Kareeya in North Queensland. The Queensland government is currently engaged in a Memorandum of Cooperation with the Papua New Guinea (PNG) government, PNG Energy Developments Limited and Origin Energy, to facilitate development of a large hydroelectricity project on the Purari River in PNG. Electricity will be supplied to the NEM through subsea transmission lines that connect to Townsville, North Queensland.

\subsection{Wind}

The Windy Hill wind farm in north Queensland has $12 \mathrm{MW}$ of installed capacity. AGL Limited has bought the development rights to the Coopers Gap wind farm site which has an estimated $500 \mathrm{MW}$ generation capacity. The OCE has also published a wind map identifying which areas might be suitable for energy generation projects.

\subsection{Geothermal}

The state has provided $A \$ 15$ million for the Queensland Geothermal Energy Centre of Excellence. The centre is a research and development hub that will examine opportunities to generate geothermal energy using new turbine, cooling tower and heat exchanger designs; power transmission and network modelling; and reservoir exploration and management. In addition, A\$5 million from the QREF has been allocated to investigate and identify suitable hot rock formations in close proximity to existing high voltage transmission networks.

\subsection{Wave and tidal}

The state has provided two small research and development grants to a total of $\mathrm{A} \$ 0.28$ million to assist in building concept demonstrators for a floating wave power generator and a tidal turbine system.

Importantly, these QREP activities have seen the RE sourced electricity generation capacities of Queensland grow by 29 per cent over 2008-2010. Table 1 shows a comparison of the installed RE capacity for the period 2008-2010 and the 2020 target. While this growth in installed capacity has merit, the supply of electricity from RE sources is still well below the 20 per cent target. The state government advised that in 2010 , the total electricity generation capacity in Queensland was 14,500 MW with coal and gas fired power stations accounting for 87 per cent of the capacity. While Queensland's RE sourced electricity generation capacity was approximately 7 per cent of total state capacity, only 4 per cent of the state's actual electricity supply was provided by renewable sources 
Table 1

Renewable energy capacity in Queensland.

\begin{tabular}{lccc}
\hline Renewable source & $\begin{array}{l}\text { 2008 capacity } \\
(\mathrm{MW})\end{array}$ & $\begin{array}{l}\text { 2010 capacity } \\
(\mathrm{MW})\end{array}$ & $\begin{array}{l}2020 \text { target } \\
(\mathrm{MW})\end{array}$ \\
\hline Biomass & 415.00 & 410.30 & 645.00 \\
Hydro & 166.00 & 166.40 & 200.00 \\
Solar hot water & 144.00 & 255.20 & 500.00 \\
Wind & 12.00 & 12.50 & 750.00 \\
Solar photovoltaic & 6.00 & 115.90 & 40.00 \\
Geothermal & 0.00 & 0.08 & 250.00 \\
Solar thermal & 0.00 & 0.00 & 250.00 \\
Total & 743.00 & 960.38 & 2635.00 \\
\hline
\end{tabular}

Source: QREP 2010 Update, 31 December 2010.

due to the lack of renewable resources availability [42]. Hence, as we noted from earlier studies, the difference between installed generation capacity and actual electricity supply targets will need clarification and agreement in the context of the QREP $[10,25]$.

However, this is not the only problem facing the Queensland government. The success of the QREP, and meeting the state's obligation under the national RET, is predicated on securing A $\$ 3.5$ billion of the $A \$ 12$ billion RE investments target set by the federal government [1,2]. Hence, under the current global financial conditions, finding over A $\$ 3$ billion worth of investments for state RE projects may not be easy in the immediate to medium term [43]. Given this context, understanding some of the practical barriers to RE developments; how state-level RETs might support the achievement of the legislated national RET; and, what actions and policies might prove effective in delivering higher levels of RE supply would appear instructive and important. We would also argue that looking at these issues through the lens of firms and stakeholder organizations involved in the RE industry should create a block of highly pragmatic and applicative knowledge.

\section{Methodology}

\subsection{Data sources and collection}

The data was collected on 30 October 2011 from the Queensland government web pages that were established for the inquiry into 'Growing Queensland's Renewable Energy Electricity Sector', conducted by the state's Environment and Resources Committee [44]. The committee was tasked to examine and report on the opportunities and challenges for the Queensland Government associated with increasing the proportion of electricity generated from renewable energy sources in Queensland' [44]. Importantly, the scope of this inquiry provided the firm and stakeholder organization data for our study (i.e. responses on RE development barriers, state-level RETs, and policies and actions that support RE expansion). Data in the form of written submissions from executives and managers in firms and stakeholder government and non-government organizations (GOs and NGOs) were collected and catalogued. A summary of the 44 firms and organizations is presented in Table 2.

\subsection{Research technique and analysis}

A qualitative research method has been used for this study in order to collect, structure, and analyse the written submissions from firms, GOs and NGOs $[45,46]$. The study is consistent with other stakeholder inquiries where written statements related to a primary issue of concern are individually and collectively analysed [47-49]. The study's data structure has been created to accurately trace firm and stakeholder organization responses to questions associated with barriers to RE supply expansion, statelevel RETs, and policies and actions for RE developments, under the precise scope of the government inquiry $[44,50]$.
Table 2

Summary of firms and stakeholder organizations.

\begin{tabular}{|c|c|}
\hline $\begin{array}{l}\text { Firm or stakeholder } \\
\text { organization }\end{array}$ & Description/Representation/Function \\
\hline \multicolumn{2}{|l|}{ Firm (18) } \\
\hline Rio Tinto & $\begin{array}{l}\text { Large international resources firm. Rev - } \\
\text { US } \$ 60 \text { billion. }\end{array}$ \\
\hline The Solar Guys & $\begin{array}{l}\text { Small Medium Enterprise. Solar hot water } \\
\text { and PV systems. }\end{array}$ \\
\hline Smart Grid Partners & $\begin{array}{l}\text { Small electricity network consultancy } \\
\text { business. }\end{array}$ \\
\hline AGL Energy & $\begin{array}{l}\text { Large Australian integrated energy firm. Rev - } \\
\text { A } \$ 1 \text { billion. }\end{array}$ \\
\hline Origin Energy & $\begin{array}{l}\text { Large Australian integrated energy firm. Rev - } \\
\text { A } \$ 10 \text { billion. }\end{array}$ \\
\hline InterGen Australia & $\begin{array}{l}\text { Australian (subsidiary) electricity generation } \\
\text { firm. }\end{array}$ \\
\hline Infigen & $\begin{array}{l}\text { Australian renewable energy firm. Rev - } \\
\text { A } \$ 270 \text { million. }\end{array}$ \\
\hline Mackay Sugar Limited & $\begin{array}{l}\text { Queensland sugar refinery/bagasse generator. } \\
\text { Rev - A } \$ 300 \text { million. }\end{array}$ \\
\hline Darwalla Milling Company & $\begin{array}{l}\text { Queensland poultry farming/biomass } \\
\text { generator. Private firm. }\end{array}$ \\
\hline Rocky Point Green Power & Queensland biomass energy generator. \\
\hline Transfield Holdings & $\begin{array}{l}\text { Australian infrastructure development firm. } \\
\operatorname{Rev}-\mathrm{A} \$ 4 \text { billion. }\end{array}$ \\
\hline $\begin{array}{l}\text { GE energy Australia and } \\
\text { New Zealand }\end{array}$ & $\begin{array}{l}\text { Australian (subsidiary) infrastructure } \\
\text { development firm. }\end{array}$ \\
\hline Conergy Australia & $\begin{array}{l}\text { Australian (subsidiary) solar and small wind } \\
\text { power systems. }\end{array}$ \\
\hline Sucrogen Australia & $\begin{array}{l}\text { Australian sugar refining and renewable } \\
\text { energy systems. }\end{array}$ \\
\hline $\begin{array}{l}\text { Vestas Australia Wind } \\
\text { Technology }\end{array}$ & $\begin{array}{l}\text { Australian (subsidiary) large scale wind power } \\
\text { systems. }\end{array}$ \\
\hline Windlab & Global wind energy development firm. \\
\hline Better Place Australia & Australian (subsidiary) electric vehicle systems. \\
\hline
\end{tabular}

GO (10)

Gold Coast City Council

Brisbane City Council

Municipal government. Population - 540,000. State capital city government. Population 2,000,000.

FraserCoast Regional Council Municipal government. Population - 100,000.

Council of Mayors SE Queensland

Queensland Youth

Environment Council

Energy Skills Queensland

Stanwell Corporation

Energex

Ergon Energy

SEQWater

NGO (16)

Growcom

Timber Queensland

Gulf Region Development

Queensland Murray-Darling

Committee

Cairns \& Far North

Environment Centre

TransitionTown Kenmore

TropicalGreen Building Network

Ten mayors from cities in South East Queensland.

Government Advisory - Youth viewpoints on the environment.

Government Business Enterprise. Electricity industry skills.

Government Business Enterprise. Electricity generation.

Government Business Enterprise. Electricity retail distribution.

Government Business Enterprise. Electricity retail distribution.

Government Business Enterprise. South East Queensland water grid.

Fruit and Vegetable Growing Industry (Queensland).

Timber Industry (Queensland).

QueenslandGulf Region Development.

Murray-DarlingBasin - Natural Resource

Management Services.

Far North Queensland - Environment

Management.

Local sustainability promotion group (Queensland).

Green building materials and manufacturing firms (Queensland).

Four regional development groups (Queensland).

Environmental conservation groups

(Queensland).

Development

Queensland Conservation

Sustainable Energy Policy Group

Bioenergy Australia

Sustainable energy group (Queensland).

Firm and government organization

bioenergy alliance (Australia).

Clean Energy Council

Clean Energy Industry (Australia). 
Table 2 (continued)

\begin{tabular}{ll}
\hline $\begin{array}{l}\text { Firm or stakeholder } \\
\text { organization }\end{array}$ & Description/Representation/Function \\
\hline $\begin{array}{l}\text { Australian Solar Cooling } \\
\text { Interest Group }\end{array}$ & Solar Cooling Industry (Australia). \\
$\begin{array}{l}\text { Australian Sugar Milling } \\
\text { Council }\end{array}$ & Sugar Mill Industry (Australia). \\
$\begin{array}{l}\text { Energy Retailers Association } \\
\text { Australia }\end{array}$ & Energy retail firms (Australia). \\
$\begin{array}{l}\text { Energy Supply Association } \\
\text { Australia }\end{array}$ & Energy supply firms (Australia). \\
\hline
\end{tabular}

Source: Queensland Government Environment and Resources Committee, 30 October 2011.

In order to structure, analyse and manage our data, we created a research database using MS Access software [50]. The written content was extracted and allocated to one of three specific database structures (i.e. barriers, state-level RETs, and policies and actions) to maintain data traceability and assure analytical integrity $[45,46,50]$. A total of 335 statements were analysed and categorized (e.g. financial, infrastructure, technical, regulatory) during the course of the study. Following this procedure, the results from each data structure was summarised and the highest ranked categories presented in the discussion of results.

\section{Results and discussion}

\subsection{Barriers to regional renewable energy supply growth}

Firms and stakeholder organizations identified a range of financial, infrastructure, technical, regulatory, economic, and information barriers to RE supply growth in Queensland. A summary of the RE supply barriers are presented in Table 3.

The six categories of barriers cover 87 per cent of all responses and are consistent with much of the RE literature [18,51]. A group of finance-related issues provided the most prominent barrier to the growth of RE supply in Queensland. Firms and stakeholders stated that the high capital costs associated with large scale RE projects in remote regions dampened potential investments (e.g. the federal solar flagships program round one winning projects will build a 250 MW solar thermal gas hybrid power plant in western Queensland, and a 150 MW solar farm in western New South Wales, at a cost of more than $\mathrm{A} \$ 2$ billion) [41]. Also, the lack of suitable longer term financial incentives in the form of state-level commercial FiT, government and taxation subsidies, favourable RE (green) certificate pricing levels, and RE systems purchase rebate schemes were also highlighted as major impediments to increased RE sourced electricity supply. Our investigations also show that the current contracting fiscal climate in Australia [52], and the inability to negotiate profitable long-term (25-30 year) Power Purchase Agreements (PPAs) with government businesses and private power companies are acting as barriers to RE developments [53].

The second major set of barriers is concentrated on the availability of suitably robust and proximately located infrastructure. In relation to large scale RE developments, federal government studies show that much of the state network is established in a narrow corridor running along the eastern seaboard of the state, and well away from the rich solar and wind resources in far west and far northern Queensland [35]. Also, a public admission by the state government's Energy Minister that the retail electricity network possesses insufficient capacity to cope with new small and medium scale solar power installations reinforces the views presented by firms and stakeholder organizations [54]. It should be noted that these infrastructure barriers also come with significant financial expenditure, given the substantial costs associated with the high voltage and retail electricity networks' upgrades.
Table 3

Barriers to RE supply growth in Queensland.

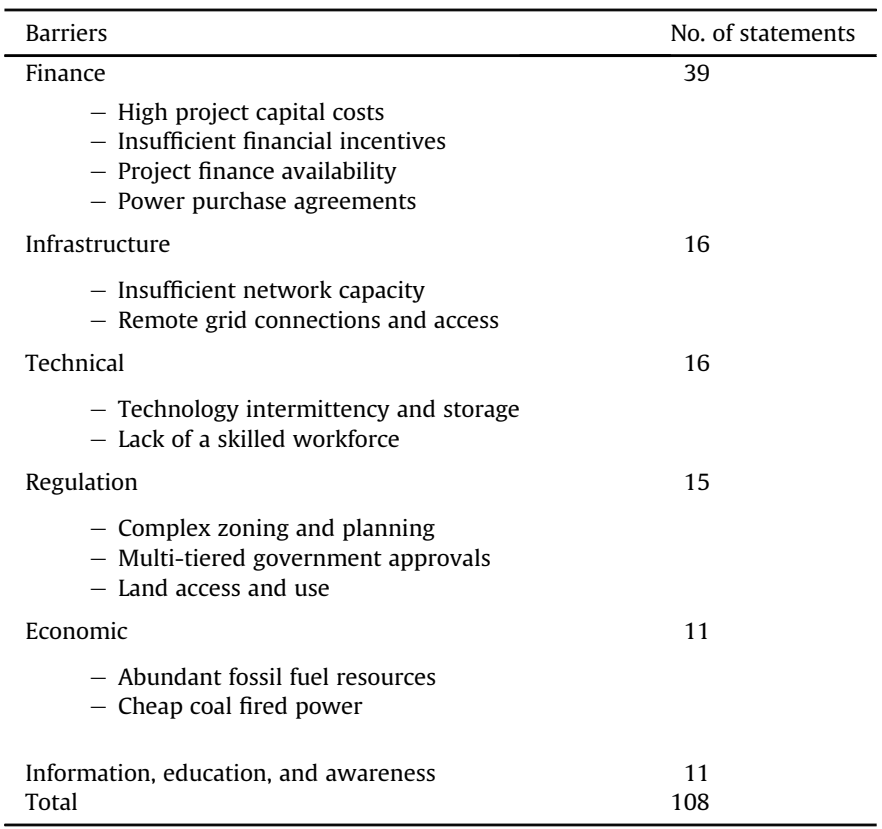

The technical barriers identified by the firms and stakeholders provide a significant challenge. First, while energy storage and relocation devices, such as hydrogen cells, combined heat and power, compressed air, pumped hydro, new and old battery, super capacitor, and superconductor systems, continue along their development pathways $[55,56]$; much of the state's remotely located RE sources requires technical storage and relocation mechanisms to support their operation and control intermittency of power delivery to the grid. Pivotally, the state government has admitted that the emerging development of storage and control technologies will assist with delivering RE developments in the future [40]. Second, the ability to maintain a competent technical workforce and skills base is difficult under the current economic conditions. The current sustained mining and resources boom in Australia is a positive drain on skilled technical workers and undermines the development of a stable RE industry workforce [52]. In sum, these technical issues pose a serious challenge to enlarged RE supply in the immediate to medium term.

Firms and stakeholder organizations assert that the regulatory hurdles to enhanced RE supply provide an administrative and legal impost to future developments. As an example, a review of the state RE project development process highlights three major electricity industry (state and national levels) gateways; three levels of government planning and approvals legislation, including a six part project development assessment system; separate water and vegetation, environmental, and indigenous culture and heritage testing protocols; and land leasing and/or acquisition procedures [57]. Accordingly, the framework for RE regulation established by the state and municipal governments provides an extensive and time intensive set of complex business processes for new RE supply projects.

As we noted earlier, the abundance of black coal resources for energy generation in Queensland is the backbone of relatively cheap electricity as a fundamental input to a vibrant state economy [36,37]. In-line with earlier studies, responses suggest that the absence of pricing carbon pollution into electricity is seen as a barrier to the delivery of capital intensive RE projects [33]. In addition, firms and stakeholder organizations also argued that the lack of RE information services and targeted education and 
awareness programs for businesses and consumers continues to hinder expanded RE supply.

\subsection{The issue of state-level RETs}

Over 57 per cent of firms and stakeholder organizations who commented on the issue of state-level RETs argued that the Queensland government should maintain its current QREP target, and remain wholly consistent with the national RET $[2,40]$. The principal argument for maintaining this target was to ensure that the lowest cost solutions (projects) for RE supply were obtained over the immediate and longer term (i.e. no distorted, higher cost RE project approvals in order to meet regional or location based targets). As an example, power firm Origin Energy typified this position in their inquiry submission:

"Origin does not recommend that the Queensland Government set a state specific obligation target around renewables. The main reason for this position is that there should be no distortion of the national RET. The building of the renewable generation fleet should not be artificially forced into specific geographical locations (or specific technologies) by the introduction of a Queensland target, as it will increase costs to customers" (Origin Energy, 30 June 2010).

Importantly, the majority of firms and stakeholder organizations asserted that all RE supply projects should be based on an economically sound and responsible business case.

In other minority views, approximately 13 per cent of responses suggested that the state government should support community development through the application of regional based RETs (e.g. 20 per cent RE supply for seaboard (current grid) communities, and 50 per cent renewable energy supply for remote communities, by 2020); while another 13 per cent argued that improved sustainability outcomes required more challenging state-level RETs ranging from 23 to 40 per cent RE supply for Queensland by 2020 . In these cases, firms and organizations argued that RETs and projects should be largely focused on regional and sustainable development in Queensland.

\subsection{Building renewable energy supply - Regional policies and actions}

Firms and stakeholder organizations identified seven major areas of activity that might increase RE supply in Queensland. A summary of the policies and actions, covering 88 per cent of all responses, are presented in Table 4.

RE finance activities and actions attracted the highest level of attention from firms and stakeholder organizations. In particular, financial incentives in the form of a large commercial scale gross FiT and suitable tax breaks (e.g. accelerated asset depreciation, goods and services tax rebates) to support large to medium RE asset investments, were seen as attractive mechanisms for increasing the number of RE supply projects and initiatives. Robust FiT structures have been identified as important financial incentives for RE investments [58]. As an example, solar PV and hot water firm The Solar Guys argued for the implementation of a large commercial scale gross solar FiT:

"Intelligent, long-term incentive mechanisms like feed-in tariffs have been poorly implemented. A case in point is the Queensland Solar Bonus Scheme - an instantaneous net solar feed-in tariff scheme. A problem with the Queensland Solar Bonus Scheme is that it doesn't allow large consumers of power to participate and is effectively limited to residential and light commercial customers. Queensland government actions - establish a commercial and industrial gross solar feed-in tariff" (The Solar Guys, 28 June 2010).
Table 4

Building RE supply in Queensland.

\begin{tabular}{|c|c|}
\hline Policies and actions & No. of statements \\
\hline Finance & 45 \\
\hline \multicolumn{2}{|c|}{$\begin{array}{l}\text { - Financial incentives } \\
\text { - Project finance support/grants } \\
\text { - Facilitate power purchase agreements }\end{array}$} \\
\hline Infrastructure & 23 \\
\hline \multicolumn{2}{|c|}{$\begin{array}{l}\text { - Network enhancements and upgrades } \\
\text { - Remote grid extensions }\end{array}$} \\
\hline Regulation & 23 \\
\hline \multicolumn{2}{|c|}{$\begin{array}{l}\text { - Streamline planning and approvals } \\
\text { - Land access and use legislation }\end{array}$} \\
\hline Community developments & 20 \\
\hline \multicolumn{2}{|l|}{$\begin{array}{l}\text { - RE districts and zones } \\
\text { - Community ownership } \\
\text { - Off-grid systems } \\
\text { - Service delivery obligations }\end{array}$} \\
\hline Technical & 15 \\
\hline \multicolumn{2}{|l|}{$\begin{array}{l}\text { - Technology R\&D funding } \\
\text { - Skilled workforce development }\end{array}$} \\
\hline Economic & 13 \\
\hline \multicolumn{2}{|l|}{$\begin{array}{l}\text { - RE investment policy } \\
\text { - Carbon price legislation }\end{array}$} \\
\hline Information, education, and awareness & 12 \\
\hline Total & 151 \\
\hline
\end{tabular}

One of the difficulties facing the Queensland government, should it seek to act on the issue of taxation, is that the federal government's Australian Taxation Office retains overall responsibility for business taxation law drafting and implementation [59]. Accordingly, this type of financial incentive would require crossjurisdictional legal consultations and approvals [4]. Also, while the state government is providing over $A \$ 200$ million in grants and funding for various RE supply projects, responses suggest that this level of commitment needs to be increased in order to meet the desired QREP outcomes. As noted earlier, the high costs associated with RE projects in remote parts of Queensland would dictate this as a prudent action [35].

As a further measure, firms and stakeholder organizations asserted that the state government should take a more active role in facilitating PPAs for RE developments. In the current process, the Queensland government does not involve itself in any commercial bargaining or negotiations between the state-owned electricity generation (e.g. CS Energy, Stanwell Corporation) and retail (e.g. Energex, Ergon Energy) companies and prospective RE developers [57]. In essence, as in other studies, state government involvement with PPA negotiations may smooth and increase the velocity of the development process [60].

While high voltage network enhancements and remote grid connections were identified by firms and stakeholder organizations as important actions for RE supply, current and future planning shows that Powerlink, the Queensland government-owned, high voltage electricity transmission network service provider, has allocated approximately $A \$ 250$ million for eleven electricity network replacement actions (substation and transformer renewals on the $275 \mathrm{kV}$ backbone and smaller $132 \mathrm{kV}$ links) over 2013-2017 [61]. In addition, two of sixteen proposed network connections for the period 2013-2017 will service RE generation plants in more remote locations (a proposed far northern Queensland wind farm and the Solar Dawn $250 \mathrm{MW}$ solar and gas hybrid plant in western Queensland) [61]. We also found that in the 
retail electricity network, Energex and Ergon Energy are spending A $\$ 15.6$ billion over 2010-2015 to reinforce and increase the capacity of the local distribution networks [62,63]. While recent studies have highlighted the importance of grid reinforcement and connections to RE supply, we acknowledge that future network reinforcement, connections and capacity enhancements will be dependent on the location of generation plants, and the economic viability of the proposed network upgrade [64].

The suggestion by firms and stakeholder organizations to review and reform the RE planning and approvals process has significant merit. In a typical response, infrastructure developer Transfield Holdings made this point in their submission:

"Transfield agrees with the broad selection of actions the Queensland Government could take to encourage investment in the generation and cogeneration of electricity from renewable energy sources. We would encourage the Committee to implement regulatory reforms to cut red tape for renewable energy projects including the streamlining local government approval processes" (Transfield Holdings, 30 June 2010).

The difficulty facing prospective RE developers is that generation plants must comply with three different layers of planning legislation [40]. As an example, renewable energy supply projects must comply with the federal Environment Conservation and Biodiversity Conservation Act (1999), while also maintaining compliance with the state's Integrated Planning Act (1997), Environmental Protection Act (1994) and Electricity Act (1994). Further separate municipal council land-use regulations and approvals are also applicable to RE projects. In response to these identified impediments, the state government is moving to improve the regulatory framework through its 'Green Door' initiative that uses an integrated development assessment system to screen and analyse the planning, ecological, economic and community wellbeing aspects of the project, and fast track the development through joint state and municipal council case management teams [65]. In addition, the state has amended the Land Act (1994) to allow lease holders to provide sub-lease access to RE supply firms and developers [66]. As noted in other studies, these types of regulatory process modifications are essential for the streamlining and smoothing of RE supply projects and investments [67].

Developing clean energy communities using RE supply projects was highlighted as a key action for the state government. Firms and stakeholder organizations argue that the creation of RE districts and zones, community ownership schemes, off-grid systems for remote communities, and the fulfilment of community service obligations using RE supplies are critical measures for growing the state's RE sourced electricity. In recent times, the state government has identified some potential districts including southwest, central, far west and far north regions of Queensland where community development and services delivery could be progressed using RE supply projects and initiatives (e.g. PV systems, solar hot water units, small turbine wind energy systems) [68]. Importantly, in these cases the integration of the RE supply sources with the community provides local control and development autonomy benefits that may otherwise not exist, particularly in remote communities [69].

While the Queensland government has commenced funding some research in the area of geothermal and wave/tidal energy resources, firms and stakeholder organizations suggest that more funds need to be allocated to RE technology research and proof-ofconcept commercialization efforts. As an example, energy retailer Energex argued that more state funding was required for RE technology research and commercial development:

"ENERGEX would like to see increased focus on the development of cost effective energy storage devices. These devices would allow the intermittent energy output from renewable generation to be stored locally and then returned to the network when needed (at times of peak demand). This technology would assist in reducing the need for retail network upgrades" (Energex, 30 June 2010).

We support findings in other studies that show technology research and commercial development funding is an identified cornerstone of RE supply growth $[8,21,23]$. Specific to this study, funding and supporting RE research and development, particularly in areas of energy storage and relocation technologies, should enable the state to keep a number of resource site and commercial development options available in the longer term [40].

Growth in RE technical skills was also seen as a key driver of enhanced RE supply. Accordingly, the QREP target of 3500 new RE industry jobs by 2020 will require a repositioning of some statelevel employment and training, jobs marketing, and tertiary education programs in order to focus on critical RE skills development [40]. While the target may be achievable in the longer term, the high growth mining and resources sector will continue to absorb large numbers of technically trained personnel in the immediate to medium term [52].

Firms and stakeholder organizations also considered that clear long-term RE investment policies, including the pricing of carbon into goods and services provision, would bring greater certainty to the electricity market and support more RE developments (e.g. the Queensland Youth Environment Council proposed a state-based carbon tax policy to make renewable energy investments more attractive) [44]. In late 2011, the Australian federal government passed legislation to establish a price on carbon emissions, and deliver transitional and investment assistance to the electricity industry in order to close high pollution plants and stimulate investment in clean energy generation [6]. These shifts in government policy and legislation provide a framework that supports RE supply growth and future developments.

Finally, firms and stakeholder organizations considered the delivery of information, education, knowledge and awareness programs to commercial businesses and individuals to be important for RE supply growth. As an example, RE systems manufacturer Conergy argued for improved community awareness and education:

"The Queensland Government needs to encourage investment in renewable energy source electricity generation using a rounded approach including community awareness and education to promote the opportunities that the increased use of renewable energy presents" (Conergy, 30 June 2010)

We note that information and awareness programs have long been championed as a mechanism to grow RE supply chains [70]. However in our study, responses suggested that the most efficient way to deliver these types of programs was to integrate them with existing energy efficiency and savings programs at the state and federal level (e.g. the Council of Australian Governments National Strategy on Energy Efficiency) [71]. In sum, the combination of energy efficiency and RE information should highlight the importance of using less energy while having regard for green and RE resources.

\section{Conclusions}

In this paper, we have attempted to examine and identify the RE supply growth barriers, targets, policies and actions that apply to the state of Queensland in Australia. However, in pursuing this research we must acknowledge some specific limitations of the study and its method. First, firms and stakeholder organizations were openly invited by the state government to provide comments and evidence for the inquiry. Accordingly, we had no control over the selection of participating organizations or their responses to the 
inquiry. Second, the study is based on a single state of Australia that is unique in terms of its population size and distribution, economy, and energy assets. Accordingly, while some of the research results may apply to other similar regions and countries, other results might not be easily generalized. Notwithstanding these limitations, this study has made a contribution to our improved understanding of what RE development barriers exist and what actions we must take to overcome them.

First, after nearly 14 years of studying the barriers to RE development and supply we note that many financial, infrastructure, technical, regulatory, economic, and information and education barriers still exist in one form or another [7,21,26,51]. Our analysis of firm and stakeholder organization responses showed that in Queensland, RE supply projects face impediments in the form of high capital costs, insufficient financial incentives, infrastructure deficiencies, shortfalls in technology and technical workforce capacity, and high levels of complex multi-tiered regulation. These results suggest that RE developments still have some way to go in terms of solving the socio-technical problems that confront this industry sector.

Second, while the majority of firms and stakeholder organizations preferred states and territories to work within the national RET framework, there may be some value in applying targets for regional development and improved sustainability outcomes. The results show that some firms and stakeholder organizations see value in using RE resources as a development conduit in regional and remote communities. Similarly, a further group of responses suggested that setting a higher level state RET would enable improved carbon pollution reduction and sustainability outcomes. In any case, further precision needs to be applied to the QREP in terms of its RE targets for installed generation capacity or electricity supply.

Third, firms and stakeholder organizations have provided the government with a broad range of actions and measures to grow Queensland's RE supply. While some regulatory reform and technology research and commercialization funding has been delivered, there is still more work to be done in the areas of establishing longterm financial incentives, infrastructure planning and realization, regulatory harmonization across the three tiers of government, community-centred developments, and information, education and awareness programs. We would argue that these actions will need to flow effectively and consistently over the next nine years if the QREP 2020 targets are to be met.

In closing, we note that Australia's clean energy future legislation was passed into law on 8 November 2011 [6]. Hence, we see further opportunities to study Australia's RE industry sector, particularly during the period following the introduction of the carbon tax in mid-2012. We consider that the longer term examination and analysis of RE developments in Australia should create several new and informative tranches of knowledge.

\section{Acknowledgements}

The authors wish to thank the Queensland Government, particularly the Energy Minister, The Honourable Stephen Robertson MP, for its support during the preparation of this article. The authors also wish to acknowledge the timely reviews of the paper and its expeditious handing by the journal's Associate Editor Professor David Elliott.

\section{References}

[1] Australian Broadcasting Commission. Senate approves renewable energy target, http://www.abc.net.au/news/2009-08-20/senate-approves-renewableenergy-target/1397962; 2009.

[2] Commonwealth of Australia. Securing a clean energy future: the Australian Government's climate change plan; 2011.
[3] Intergovernmental Panel on Climate Change (IPCC). IPCC fourth assessment report. Cambridge UK: CambridgeUniversity Press; 2007.

[4] Watt M, Outhred H. Australian and international renewable energy policy initiatives. Renewable Energy 2001;22:241-5.

[5] Bird L, Bolinger M, Gagliano T, Wiser R, Brown M, Parsons B. Policies and market factors driving wind power development in the United States. Renewable Energy 2005;33:1397-407.

[6] Commonwealth of Australia. Senate Hansard transcripts, http://www.aph.gov. au/hansard/senate/dailys/ds081111.pdf; 2011.

[7] Dincer I. Renewable energy and sustainable development: a crucial review. Renewable and Sustainable Energy Reviews 2000;4:157-75.

[8] Foxon T, Gross R, Chase A, Howes J, Arnall A, Anderson D. UK innovation systems for new and renewable energy technologies: drivers, barriers and systems failures. Energy Policy 2005;33:2123-37.

[9] Fouquet D, Johansson T. European renewable energy policy at crossroads Focus on electricity support mechanisms. Energy Policy 2008;36:4079-92.

[10] Loiter J, Norberg-Bohm V. Technology policy and renewable energy: public roles in the development of new energy technologies. Energy Policy 1999;27: 85-97.

[11] Kaya D. Renewable energy policies in Turkey. Renewable and Sustainable Energy Reviews 2006;10:152-63.

[12] Agnolucci P. Renewable electricity policies in The Netherlands. Renewable Energy 2007;32:868-83.

[13] Lewis J, Wiser R. Fostering a renewable energy technology industry: an international comparison of wind industry policy support mechanisms. Energy Policy 2007;35:1844-57.

[14] Frondel M, Ritter N, Schmidt C, Vance C. Economic impacts from the promotion of renewable energy technologies: the German experience. Energy Policy 2010;38:4048-56.

[15] Audit Office of New South Wales. Financial Audit. In: Focusing on electricity, vol. $4 ; 2011$.

[16] Lund $H$. Renewable energy strategies for sustainable development. Energy 2007;32:912-9.

[17] Lund P. Effects of energy policies on industry expansion in renewable energy. Renewable Energy 2009;34:53-64.

[18] Reddy S, Painuly J. Diffusion of renewable energy technologies - barriers and stakeholders' perspectives. 2004;29:1431-1447.

[19] Mitchell C, Connor P. Renewable energy in the UK1990-2003. Energy Policy 2004;32:1935-47.

[20] Jacobsson S, Bergek A, Finon D, Lauber V, Mitchell C, Toke D, et al. EU renewable energy support policy: faith or facts? Energy Policy 2009;37: 2143-6.

[21] Jacobsson S, Johnson A. The diffusion of renewable energy technology: an analytical framework and key issues for research. Energy Policy 2000;28: 625-40.

[22] Jacobsson S, Bergek A. Transforming the energy sector: the evolution of technological systems in renewable energy technology. Industrial and Corporate Change 2004;13:815-49.

[23] Burer M, Wustenhagen R. Which renewable energy policy is a venture capitalist's best friend? Empirical evidence from a survey of international cleantech investors. Energy Policy 2009;37:4997-5006.

[24] Zhang P, Yang Y, Shi J, Zheng Y, Wang L, Li X. Opportunities and challenges for renewable energy policy in China. Renewable and Sustainable Energy Reviews 2009;13:439-49.

[25] Menanteau P, Finon D, Lamy M. Prices versus quantities: choosing policies for promoting the development of renewable energy. Energy Policy 2003;31: 799-812.

[26] Sayigh A. Renewable energy - The way forward. Applied Energy 1999;64: $15-30$.

[27] Martinot E, Dienst C, Liu W, Chai Q. Renewable energy futures: targets, scenarios and pathways. Annual Review of Environment and Resources 2007; 32:205-39.

[28] Wu J, Huang Y. Renewable energy perspectives and support mechanisms in Taiwan. Renewable Energy 2006;31:1718-32.

[29] Komor P, Bazilian M. Renewable energy policy goals, programs, and technologies. Energy Policy 2005;33:1873-81.

[30] Blok K. Renewable energy policies in the European Union. Energy Policy 2006; $34: 251-5$.

[31] Reiche D, Bechberger M. Policy differences in the promotion of renewable energies in the EU member states. Energy Policy 2004;32:843-9.

[32] Kent A, Mercer D. Australia's mandatory renewable energy target (MRET): an assessment. Energy Policy 2006;34:1046-62.

[33] Owen A. Renewable energy: externality costs as market barriers. Energy Policy 2006;34:632-42.

[34] Effendi P, Courvisanos J. Political aspects of innovation: examining renewable energy in Australia. Renewable Energy 2012;38:245-52.

[35] Commonwealth of Australia. Energy in Australia. Canberra: Australian Bureau of Agricultural and Resource Economics and Sciences; 2011.

[36] Queensland Government. 2011. http://www.qld.gov.au/about-queensland/.

[37] Queensland Government. http://www.climatechange.qld.gov.au/whatsbeingdone/ climatechangestrategy/. 2010.

[38] Australian Electricity Market Operator. 2011. http://www.aemo.com.au/ corporate/aboutaemo.html.

[39] Australian Electricity Market Operator. An introduction to Australia's National Electricity Market. Melbourne: AEMO; 2010 
[40] Queensland Government. The Queensland Renewable Energy Plan (QREP). Brisbane: The State of Queensland; 2009.

[41] Commonwealth of Australia. Solar flagships program, http://www.ret.gov.au/ energy/clean/cei/sfp/Pages/sfp.aspx; 2011.

[42] Queensland Government. Electricity generation in Queensland, http://www. energyfutures.qld.gov.au/energy-in-queensland/electricity-generation.htm; 2011.

[43] Bruce A. Rich world economic malaise to endure into 2012: Reuters poll Thomson Reuters; 2011.

[44] Queensland Government. 2011. http://www.parliament.qld.gov.au/work-ofcommittees/former-committees/ERC/inquiries/past-inquiries/Renewable Energy.

[45] Miles M, Huberman A. Qualitative data analysis. 2nd ed. Thousand Oaks, CA: Sage; 1997.

[46] Denzin N, Lincoln Y. Handbook of qualitative research. 3rd ed. Thousand Oaks, CA: Sage; 2005

[47] Clarkson MA. Stakeholder framework for analyzing and evaluating corporate social performance. Academy of Management Review 1994;30:92-117.

[48] Donaldson T, Preston L. The stakeholder theory of the corporation: concepts, evidence and implications. Academy of Management Review 1995;20:65-91.

[49] Freeman R, Wicks A, Parmar B. Stakeholder theory and "the corporate objective revisited". Organization Science 2004;15:364-9.

[50] Corley K, Gioia D. Identity ambiguity and change in the wake of a corporate spin-off. Administrative Science Quarterly 2004;49:173-208.

[51] Painuly J. Barriers to renewable energy penetration; a framework for analysis. Renewable Energy 2001;24:73-89.

[52] Reserve Bank of Australia. Statement on monetary policy - Economic outlook; May 2011.

[53] Kuypers R. Wind power. Infigen, http://www.engineersaustralia.org.au/ events/itee-ssee-wind-power; 2011

[54] Hall P. Queensland State Government admits electricity grid failing to cope with solar power systems. Courier Mail; 24 September 2011.
[55] Carrasco J, Franquelo L, Bialasiewicz J, Galvan E, Portillo Guisado R, Prats M, et al. Power-electronic systems for the grid integration of renewable energy sources: a survey. IEEE Transactions Industrial Electronics 2006;53: $1002-16$.

[56] Barton J, Infield D. Energy storage and its use with intermittent renewable energy. IEEE Transactions Energy Conversion 2004;19:441-8.

[57] Queensland Government. Renewable energy project development guide; 2011.

[58] Mendonca M. Feed-in tariffs: accelerating the deployment of renewable energy. London: Earthscan; 2007.

[59] Australian Taxation Office. 2011. http://www.ato.gov.au/businesses/.

[60] Wiser R, Pickle S. Financing investments in renewable energy: impacts of policy design. Renewable and Sustainable Energy Reviews 1998;2:361-86.

[61] Powerlink Queensland. Annual planning report; 2011.

[62] Energex network management plan 2011-2016; August 2011.

[63] Ergon energy network management plan 2011-2016; September 2011.

[64] Hammons T. Integrating renewable energy sources into European grids. Electrical Power and Energy Systems 2008;30:462-75.

[65] Queensland Government. Green door information paper; July 2011.

[66] Queensland Government. Land act 1994; 1 November 2011.

[67] Upham P, Shackley S. The case of a proposed 21.5MWe biomass gasifier in Winkleigh, Devon: implications for governance of renewable energy planning. Energy Policy 2006;34:2161-72.

[68] Queensland Government. Renewable energy industry development plan; 24 October 2011.

[69] El Bassam N, Maegaard P. Integrated renewable energy for rural communities: planning guidelines, technologies and applications. Amsterdam: Elsevier; 2004.

[70] Walker G. Renewable energy and the public. Land Use Policy 1995;12: 49-59.

[71] Council of Australian Governments. 2009. http://www.coag.gov.au/coag meeting_outcomes/2009-07-02/docs/Energy_efficiency_measures_table.pdf. 